\title{
Livestock Demand, Global Land Use Changes, and Induced Greenhouse Gas Emissions
}

\author{
Sunil P. Dhoubhadel1*, Farzad Taheripour², Matthew C. Stockton ${ }^{3}$ \\ ${ }^{1}$ Department of Agriculture, Fort Hays State University, Hays, USA \\ ${ }^{2}$ Department of Agricultural Economics, Purdue University, West Lafayette, USA \\ ${ }^{3}$ West Central Research \& Extension Center, University of Nebraska-Lincoln, North Platte, USA \\ Email: *spdhoubhadel@fhsu.edu
}

Received 12 April 2016; accepted 3 June 2016; published 6 June 2016

Copyright (C) 2016 by authors and Scientific Research Publishing Inc.

This work is licensed under the Creative Commons Attribution International License (CC BY). http://creativecommons.org/licenses/by/4.0/

(c) (i) Open Access

\begin{abstract}
With increasing global population and income, the demand for livestock products continues to grow and is likely to grow in future as well. This raises concerns about the implications of such growth for the environment. A well-known Computable General Equilibrium model (CGE), GTAPBIO, is used to project the growth of livestock output between 2004 and 2022 and to estimate the land use changes and associated Greenhouse Gas (GHG) emissions. Results indicate that the increased livestock output leads to considerable increase in pasture (about 45 million hectares) and decrease in forest area (about 44 million hectares) between 2004 and 2022. Estimated emissions associated with this change are about 20 billion tons of carbon dioxide equivalent $\left(\mathrm{CO}_{2}\right.$ e) during 2004-2022 or an annual average of 1.1 billion tons. Results also indicate that a significant portion of the emissions (about 11\%) can be reduced if consumer preferences could be altered. In practice, this will require policy interventions that promote substitution of non-ruminant for ruminant meat products.
\end{abstract}

\section{Keywords}

Livestock Demand, Land Use, GHG Emissions, CGE Model

\section{Introduction}

With growing concern about the climate change, potential sources of Greenhouse Gas (GHG) emissions mitigation are being identified. Lately, the livestock sector has received considerable attention in this regard as the sector reportedly contributes significantly to human-induced GHG emissions [1]-[3].

\footnotetext{
${ }^{*}$ Corresponding author.
}

How to cite this paper: Dhoubhadel, S.P., Taheripour, F. and Stockton, M.C. (2016) Livestock Demand, Global Land Use Changes, and Induced Greenhouse Gas Emissions. Journal of Environmental Protection, 7, 985-995.

http://dx.doi.org/10.4236/jep.2016.77087 
The global demand for livestock products has grown over the years and is likely continue that growth in the future [4]. Increasing overall livestock output has implications for the environment. The sources of GHG emissions from the livestock sector can be segregated into two broad categories: 1) emissions that emanate from land use changes due to livestock production; typically when forest land is converted into pasture or cropland to accommodate increased livestock production, it results in increased GHG emissions due to land clearing and reduced long term carbon sequestration; 2) emissions which are attributed to non-land use change sources such as enteric fermentation, feed production and processing, manure handling, and processing and transportation of animal products.

Unlike the emissions estimates for non-land use sources, which have been well documented in the literature [1] [2], the emissions induced by land use changes due to livestock production have not been adequately addressed and are a contentious issue [5]. While [3] and [6] estimate about 2.4 to 2.6 billion tons carbon dioxide equivalent $\left(\mathrm{CO}_{2}\right.$ e) emissions per year as a result of land use change due to livestock production, these reports, however, do not provide a detailed explanation of the methods used to obtain these estimates. A FAO report authored by [2] estimates approximately 7.1 billion tons of $\mathrm{CO}_{2}$ e emissions annually from the livestock sector and attribute about 0.65 billion tons $\mathrm{CO}_{2}$ e per year (about 9.2\% of the total emissions from the sector) to the land use changes. However, this estimate fails to account fully the emissions from land use change associated with livestock production at the global level as it mainly accounts for land use changes in Latin America due to soybean production in Brazil and Argentina and pasture expansion in Brazil, Chile, Nicaragua, and Paraguay. Given that the report does not account for land use changes in all regions of the world and all crops, it is likely that it underestimates the emissions from land use change caused by livestock production at the global level. Moreover, [2]'s emission estimates are based on the reference years 1996-2006, which need updating to account for the livestock production after 2006. A more recent estimate of GHG emissions from livestock sector by [1] does not include the emissions from land use changes. Given this gap in the literature, this work focuses on estimating GHG emissions induced by land use changes due to projected increase in livestock production between 2004 and 2022.

The objectives of this paper are threefold: 1) provide a baseline projection for regional livestock output growth between 2004 and 2022 at the global scale; 2) use the baseline projection estimates of livestock output to estimate the expected global land use changes by regions; and 3) estimate the GHG emissions associated with those changes. Considering the global scale of this work and the number of interactions among many economic sectors and regions, a Computable General Equilibrium (CGE) modeling framework is used.

\section{The Model}

A modified version of the standard GTAP (Global Trade Analysis Project) model, GTAP-BIO, is used for this analysis. The GTAP model is a multi-sector, multi-region CGE model, which is widely used for policy, trade, and environmental analysis. GTAP models consumer (private households) preference using a Constant Difference of Elasticity (CDE) function, which allows income elasticities to differ across goods. Producer/firm production functions are modeled using nested Constant Elasticity of Substitution (CES) forms. Moreover, it assumes constant returns to scale in production and perfectly competitive markets. The Armington assumption is used for traded goods i.e. the imports are differentiated by country of origin. The general equilibrium nature of the model is imposed by applying Walras Law in the model, i.e. in equilibrium all markets clear (i.e. aggregate demand equals aggregate supply in all input and output markets, imports equal exports in the international market), all firms earn zero economic profits, and all consumers operate on their budget constraints, and global investments equal global savings. The standard GTAP model is fully described and discussed with underlying assumptions and equations in the book "Global Trade Analysis" [7], the discussion in this section is focused on the features of GTAP-BIO model that are pertinent to the objectives of this study.

The GTAP-BIO was originally developed and used to estimate the impact of increased biofuels production on global land use and associated GHG emissions [8] [9]. The GTAP-BIO explicitly models the competition among crops, livestock, and the biofuels sector in the land market. Besides modeling the land use, the model explicitly incorporates feed demand for livestock. The livestock feed demand includes not only conventional feed sources but also distillers' grains, a by-product of corn ethanol production, primarily used as a livestock feed ingredient (for details see [10]). Given that the GTAP-BIO model explicitly models land supply and the livestock feed demand in addition to retaining the general equilibrium features of the standard GTAP model, the model is very appropriate to estimate the growth of livestock demand and associated land use changes. 
Figure 1 illustrates the land supply module in the GTAP-BIO model. This module determines the supply of land for forest, crop, and pasture production purposes in 18 Agro-Ecological Zones (AEZs) around the world. The elasticity of transformation, ETL1 determines the transformation of land for forest, crops and pasture, while ETL2 governs allocation of crop land among different crops. ETL3 is the elasticity of transformation of pasture land for meat and milk production. These elasticities are tuned according to the changes in land cover and harvested areas at the global scale [11].

\section{Experiments and Data Sources}

To examine the impact of increased livestock output on global land use and resulting GHG emissions, two experiments are developed and applied using the GTAP-BIO model and GTAP database version 7, which corresponds to the reference year 2004.

1) Experiment 1: This experiment is carried out by using the forecasted changes (Figure 2) in GDP, population, capital, skilled labor, and unskilled labor between the years 2004 (baseline) and 2022 as exogenous shocks to the GTAP-BIO model for all GTAP regions (Table 1). The land use changes obtained from this experiment can be attributed to changes in demand for all goods and services in the regional economies including changes in livestock production.

2) Experiment 2: Experiment 1 is repeated, while the household and intermediate demands for livestock products held constant ${ }^{1}$. The difference in land use between this experiment and the first experiment can be attributed to the effect of the livestock demand on land use.

Two additional steps are followed. First, the resulting land use changes are introduced into the emissions factors developed by Plevin et al. [12] to calculate induced land use emissions due to changes in livestock outputs

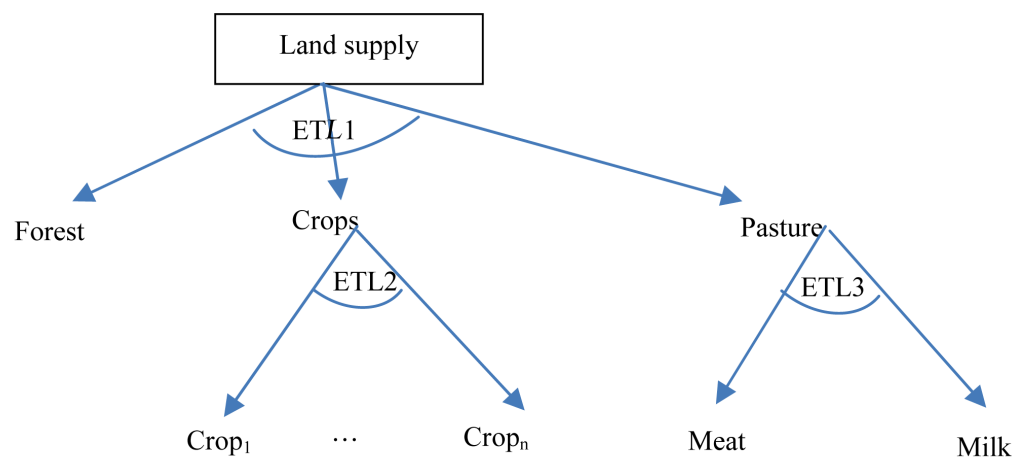

\section{Figure 1. Land supply in the GTAP-BIO Model.}

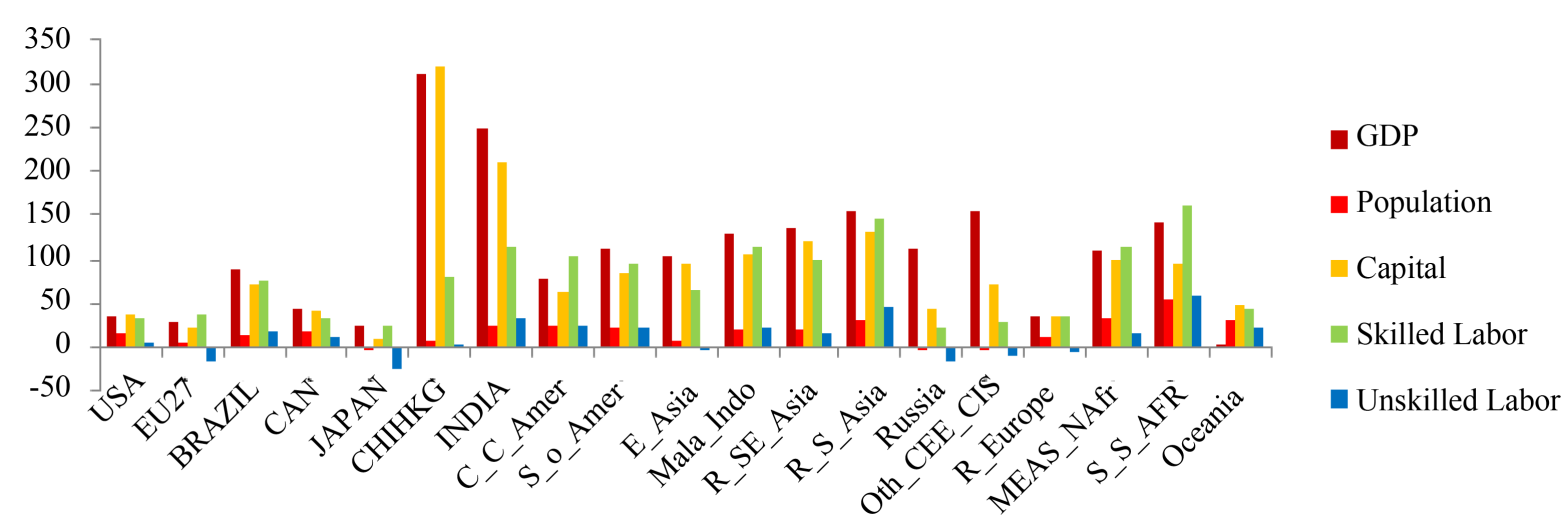

Figure 2. Projected growth (in percentage) in GDP, population, capital, and skilled and unskilled labor (2004-2022). Source: GDP, population and capital changes from CEPII baseline version 2.1 [13]. The data for skilled and unskilled labor are obtained from the baseline projection database prepared by [14].

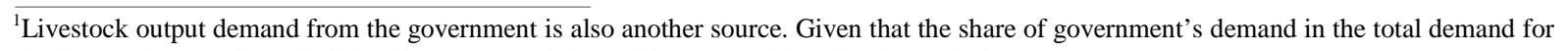
the livestock output is negligible, this category of demand is not considered in the analysis. 
Table 1. Definition of regions included in the GTAP-BIO Model.

\begin{tabular}{cc}
\hline GTAP-BIO regions & Description of the regions \\
USA & United States \\
EU27 & European Union 27 \\
BRAZIL & Brazil \\
CAN & Canada \\
JAPAN & Japan \\
CHIHKG & China and Hong Kong \\
INDIA & India \\
C_C_Amer & Central and Caribbean Americas \\
S_o_Amer & South and Other Americas \\
E_Asia & East Asia \\
Mala_Indo & Malaysia and Indonesia \\
R_SE_Asia & Rest of South East Asia \\
R_S_Asia & Rest of South Asia \\
Russia & Russian Federation \\
Oth_CEE_CIS & Sub Saharan Africa \\
R_Europe & Oceania countries \\
MEAS_NAfr & Middle Eastern and North Africa \\
S_S_AFR & Other East Europe and Rest of Former Soviet Union \\
Oceania &
\end{tabular}

for the time period of 2004-2022. These authors have developed a comprehensive model, “the AEZ_EF v47”, specifically designed to estimate GHG emissions associated with land use changes. The model considers various sources and sinks of GHG emission such as the above and below-ground live biomass, dead organic matter, soil organic matter, harvested wood products, non- $\mathrm{CO}_{2}$ emissions (e.g. methane and nitrous oxide), and foregone sequestration in estimating the induced land use emissions. Moreover, the model is designed to fit well with the GTAP-BIO model such that the regions and AEZs in the AEZ_EF v47 model exactly match with the 19 regions and 18 AEZs in the GTAP model. This facilitates direct use of the land use change results from the GTAP model simulations into the AEZ_EF v47 model. Second, a series of simulations with changes in the substitution parameter of the GTAP-BIO model are tested to examine the sensitivity of the results.

The projected data for GDP, population, and capital (Figure 2) mainly come from the Centre d'Études Prospectives et d'Informations Internationales (CEPII) baseline database version 2.1 [13]. The projected changes in skilled and unskilled labor between the years 2004 to 2022 (Figure 2) are from the baseline projection database prepared by [14] for the GTAP model. Both the CEPII and [14] information are presented originally as a country level data and therefore are aggregated into the 19 GTAP regions. The percentage change in each of the five variables between 2004 and 2022 is calculated and then used as a shock to these variables in the model thereby simulating projected growth in livestock output and associated land use change.

\section{Results}

\subsection{Change in Livestock Output ${ }^{2}$}

Figure 3 presents projected changes in the livestock output at the global scale for the time period of 2004 to 2022, obtained from the first experiment. The largest increase is observed for non-ruminant products (111\%) followed by ruminant (84\%) and dairy products (64\%).

\footnotetext{
${ }^{2}$ The GTAP-BIO results (except for the land use change) are presented in proportionate change, hence, the results on livestock output changes are in percentage change rather than the absolute change.
} 
Figure 4 shows the projected increases in livestock output for each of the 19 regions. Among these regions, China-Hong Kong (CHIHKG) and INDIA are the regions with the greatest increases in livestock output. CHIHKG has more than a $200 \%$ increase in all three categories of livestock output with INDIA not far behind with nearly a $200 \%$ increase. This increase is mainly driven by the large simultaneous increases in income (GDP) and population (Figure 2) in these regions. Among livestock output categories, CHIHKG has the highest growth for ruminants, but INDIA has the largest increase in non-ruminants. The rest of South Asia (R_S_Asia), Other East Europe and the rest of the former Soviet Union excluding Russia (Other_CEE_CIS), Middle-Eastern and North Africa (MEAS_NAfr), and Sub-Saharan Africa (S_S_AFR) are the other regions with relatively high growth in livestock outputs.

\subsection{Land Use Impacts}

Table 2 and Figure 5 show the impact of livestock output growth on land use. The figures represent the difference in land use between the first and second experiments explained above. As is evident in the table and the figure, with the increase in livestock output, pasture area is expanded while forest land is reduced in all regions. However, the overall change in crop land has a mixed outcome. In most of the regions, cropland is reduced, while in regions such as Canada (CAN), CHIHKG, and Mala_Indo cropland expanded. Globally there is a net increase of about 44.5 billion hectares of pasture, with a decrease in cropland and forest of 1.1 billion and 43.3 billion hectares respectively (Table 2). Among the regions, CHIHKG emerges as the region of largest pasture expansion/deforestation followed by S_S_AFR, BRAZIL, South and Other Americas (S_o_Amer), and R_S_ Asia (Table 2). The expansion of pasture is small in the advanced economies such as the EU27, CAN, JAPAN, Oth_Europe, and Oceania.

\subsection{Emissions Due to the Land Use Changes}

As stated previously, the results on regional land use change obtained from the GTAP-BIO model simulations are used in combination with the "AEZ_EF v47" model to estimate the induced land use emissions as a result of regional changes in livestock demands for livestock outputs ${ }^{3}$. Table 3 presents the induced land use emissions as

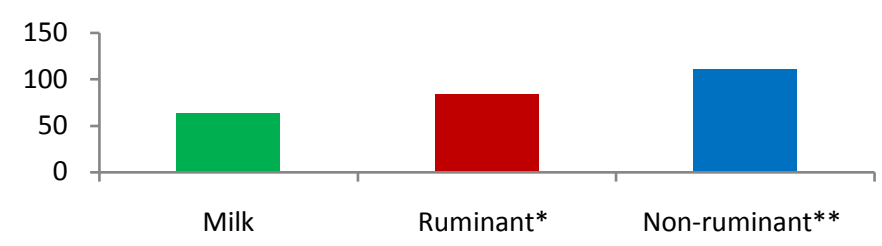

Figure 3. Projected growth (in percentage) in the global livestock output (2004-2022).

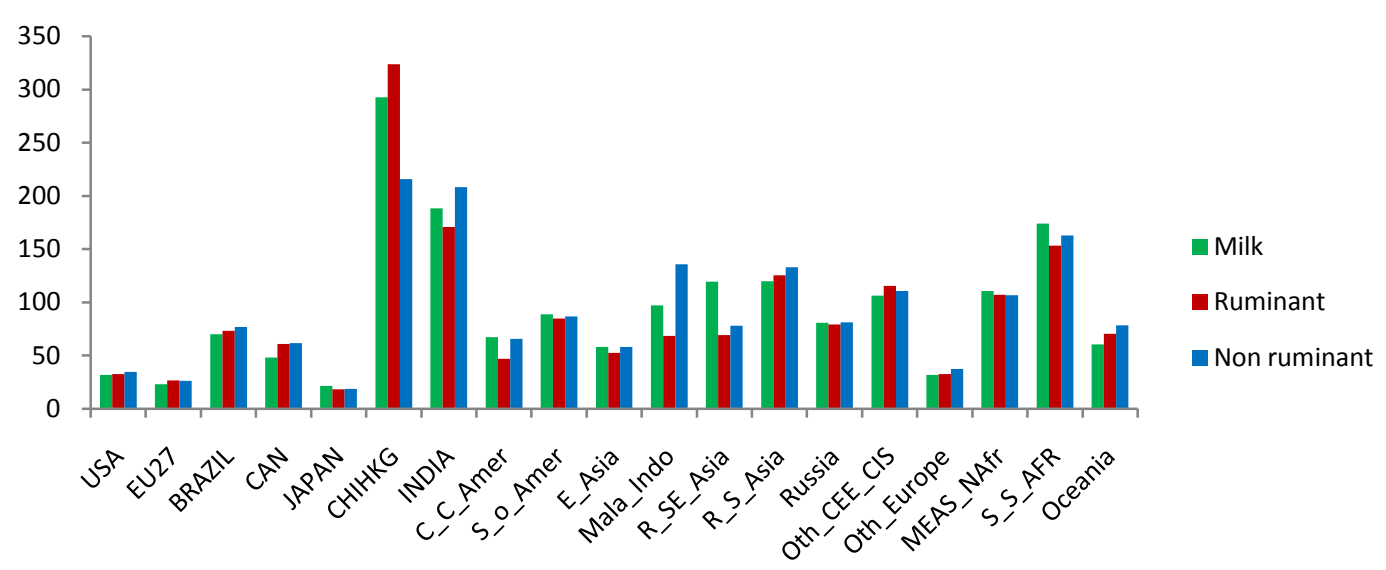

Figure 4. Projected growth (in percentage) in the regional livestock output (2004-2022).

${ }^{3}$ For this purpose regional land use change results similar to the ones presented in Table 2 and Table 4 but disaggregated to the 18 AEZ levels of the GTAP-BIO model are used in the "AEZ_EF V47" model. 


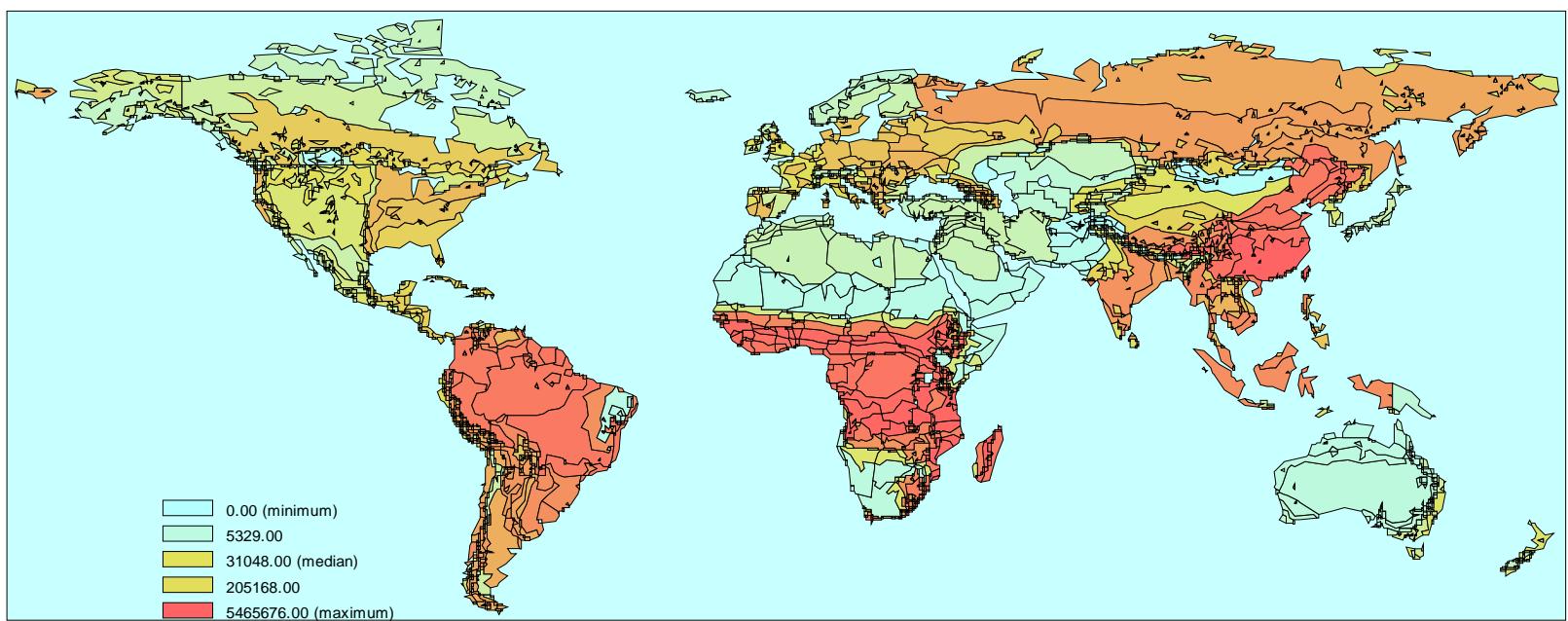

(a)

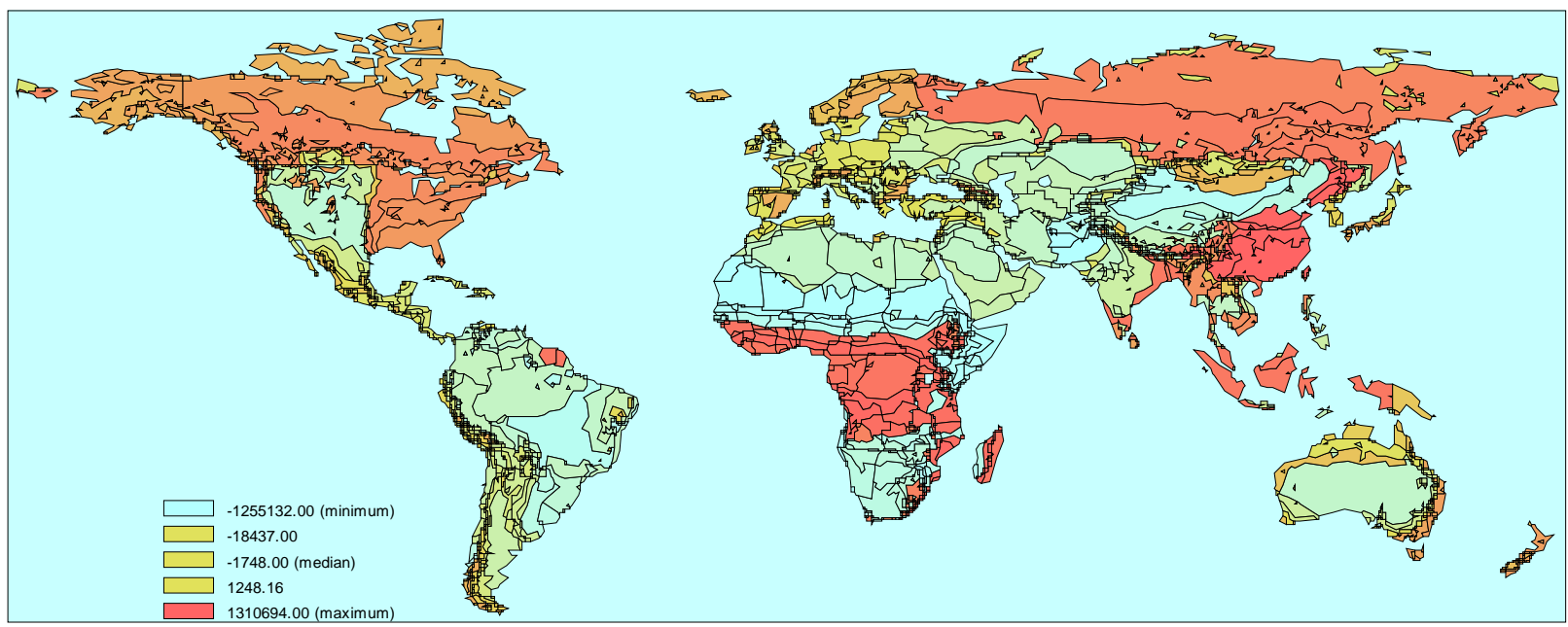

(b)

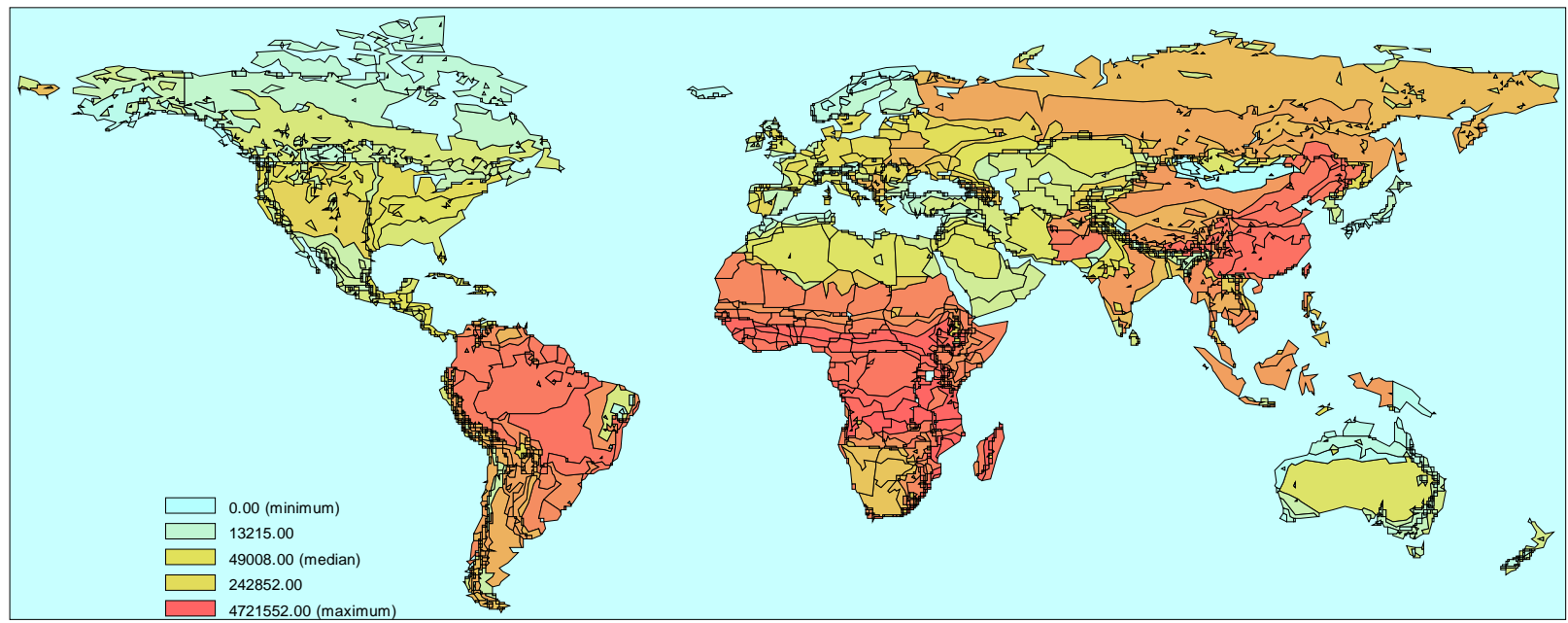

(c)

Figure 5. (a) Decrease in forest land due to increase in livestock demand (2004-2022); (b) Change in crop land due to increase in livestock demand (2004-2022). Negative values are for decrease in cropland and positive values indicate increase in cropland; (c) Increase in pastureland due to increase in livestock demand (2004-2022). 
Table 2. Projected change in land use (in hectare) induced by change in the demand for livestock outputs (2004-2022).

\begin{tabular}{|c|c|c|c|}
\hline \multirow{2}{*}{ GTAP-BIO regions } & \multicolumn{3}{|c|}{ Land use changes } \\
\hline & Forest & Cropland & Pasture \\
\hline USA & $(280,016)^{\mathrm{a}}$ & $(26,032)$ & 305,936 \\
\hline EU27 & $(121,680)$ & (7488) & 129,212 \\
\hline BRAZIL & $(4,204,000)$ & $(430,460)$ & 4,634,288 \\
\hline CAN & $(113,376)$ & 41,208 & 72,114 \\
\hline JAPAN & $(7640)$ & $(1861)$ & 9503 \\
\hline CHIHKG & $(18,803,440)$ & $2,440,520$ & $16,363,040$ \\
\hline INDIA & $(678,732)$ & $(75,184)$ & 753,938 \\
\hline C_C_Amer & $(166,356)$ & $(22,488)$ & 188,832 \\
\hline S_o_Amer & $(3,472,112)$ & $(272,012)$ & $3,744,208$ \\
\hline E_Asia & $(136,132)$ & (7582) & 143,720 \\
\hline Mala_Indo & $(429,544)$ & 95,640 & 333,937 \\
\hline R_SE_Asia & $(687,912)$ & $(31,856)$ & 719,812 \\
\hline R_S_Asia & $(423,938)$ & $(1,582,812)$ & $2,006,784$ \\
\hline Russia & $(466,064)$ & $(21,344)$ & 487,464 \\
\hline Oth_CEE_CIS & $(243,572)$ & $(148,840)$ & 392,352 \\
\hline Oth_Europe & (3368) & (1289) & 4659 \\
\hline MEAS_NAfr & $(13,054)$ & $(80,708)$ & 93,744 \\
\hline S_S_AFR & $(13,071,280)$ & $(907,216)$ & $13,978,688$ \\
\hline Oceania & $(38,498)$ & $(60,884)$ & 99,456 \\
\hline World & $(43,360,713)$ & $(1,100,688)$ & $44,461,687$ \\
\hline
\end{tabular}

${ }^{\mathrm{a}}$ Values in the parenthesis are the negative changes.

a consequence of changes in livestock demand between 2004 and 2022. Results indicate a major contribution of deforestation to the total emissions; particularly, the conversion of forest to pasture accounts for the majority of the emissions (Table 2 and Table 3). Conversely, the conversion of cropland to pasture reduces emissions. The regions with relatively higher emission are S_S_Afr, CHIHKG, BRAZIL, and S_o_Amer (Table 3). Mal_Indo, R_SE_Asia, and R_S_Asia are other regions with major land use emissions. At the global level, the induced emissions are about 19.8 billion tons $\mathrm{CO}_{2}$ e (Table 3). Since these emissions are the aggregated emissions for the 18 year period (2004-2022), the average annualized emissions due to the increase in livestock demand are about 1.1 billion tons $\mathrm{CO}_{2}$ e per year. Given that the 0.65 billion tons $\mathrm{CO}_{2}$ e per year estimate by [2] might be underestimated, the estimate of 1.1 billion tons $\mathrm{CO}_{2}$ e per year obtained from this study is very plausible.

\subsection{Sensitivity Analysis}

As with all models of this type, the results are a function of the magnitude of the parameters. Therefore, if the parameter values are altered, it is expected that the results would be altered. It is in this spirit that a sensitivity analysis is undertaken. The demand for livestock products comes directly from the preferences of those purchasing it, the final consumers. The elasticity associated with the substitution among livestock products is relaxed by making them more elastic to incorporate some change in consumer preferences over the time. The increase in elasticity value in effect amounts to an increase in price sensitivity for any individual product type.

This increase in elasticity is accomplished by altering the substitution parameter (SUBPAR) in the model. The SUBPAR parameter in the model helps determine how easily goods are substitutable in consumption. The SUBPAR values for livestock products in the model are decreased by $50 \%$ for all regions compared to the baseline case. The decrease in SUBPAR increases own and cross price compensated elasticities. 
Table 3. Total induced emission (in 1000 tons $\mathrm{CO}_{2}$ e) from land use changes due to changes in livestock output (20042022).

\begin{tabular}{|c|c|c|c|c|c|}
\hline \multirow{2}{*}{ GTAP-BIO Regions } & \multicolumn{4}{|c|}{ Land Conversion Sequences ${ }^{\mathrm{b}}$} & \multirow{2}{*}{ Total } \\
\hline & F-to-C & C-to-P & C-to-CP & F-to-P & \\
\hline USA & 19,716 & -3774 & $-66,315$ & 62,612 & 12,239 \\
\hline EU27 & 404 & -1128 & 0 & 25,155 & 24,431 \\
\hline BRAZIL & 0 & $-77,551$ & $-163,062$ & $2,907,306$ & 2,666,693 \\
\hline CAN & 21,047 & -276 & 0 & 19,294 & 40,064 \\
\hline JAPAN & 505 & -702 & 0 & 1469 & 1272 \\
\hline CHIHKG & $1,783,421$ & $-33,138$ & 0 & 4,898,689 & $6,648,973$ \\
\hline INDIA & 98,341 & $-16,468$ & 0 & 277,917 & 359,791 \\
\hline C_C_Amer & 0 & -5465 & 0 & 92,577 & 87,112 \\
\hline S_o_Amer & 164 & $-63,217$ & 0 & $1,815,169$ & $1,752,116$ \\
\hline E_Asia & 216 & -637 & 0 & 14,834 & 14,414 \\
\hline Mala_Indo & 255,131 & -9428 & 0 & 250,385 & 496,087 \\
\hline R_SE_Asia & 17,938 & $-11,469$ & 0 & 406,877 & 413,346 \\
\hline R_S_Asia & 179,956 & $-83,821$ & 0 & 103,653 & 199,788 \\
\hline Russia & 19,241 & -7282 & 0 & 44,155 & 56,114 \\
\hline Oth_CEE_CIS & 0 & $-11,919$ & 0 & 47,571 & 35,653 \\
\hline Oth_Europe & 1 & -260 & 0 & 437 & 177 \\
\hline MEAS_Nafr & 0 & -6064 & 0 & 4972 & $-1,092$ \\
\hline S_S_Afr & 382,294 & $-113,408$ & 0 & $6,678,720$ & $6,947,606$ \\
\hline Oceania & 2174 & -3193 & 0 & 15,212 & 14,193 \\
\hline World & $2,781,398$ & $-437,208$ & $-229,377$ & $17,688,554$ & $19,768,978$ \\
\hline
\end{tabular}

${ }^{\mathrm{b}} \mathrm{F}=$ forest, $\mathrm{C}=$ cropland, $\mathrm{P}=$ pasture, and $\mathrm{CP}=$ cropland-pasture (land that can alternate between crop cultivation and pasture).

Figure $6^{4}$ and Figure 7 present the percentage point difference in the global and regional livestock outputs when SUBPAR is reduced. Compared to the baseline simulations, with the reduced parameter values, the global livestock output increased for all categories. The increased price sensitivity in consumption to both own-price and cross-price changes significantly increased the global output for non-ruminants (Figure 6). At the regional level, INDIA, CHIHKG, MEAS_NAfr, Oth_CEE_CIS, R_S_Asia, Russia, S_O_Amer, and BRAZIL are the regions with the largest increase in non-ruminant output compared to the baseline scenario (Figure 7).

Table 4 shows the difference in land use change with higher price sensitivity. The results on the "A" columns are the baseline results, the "B" columns are the price sensitive results, and the "C" columns list the difference between two scenarios $(C=B-A)$. With the increased price sensitivity, about 3.8 million hectares of forest are spared, while both cropland and pasture area decline by just over 3 million hectares and 767 thousand hectares, respectively. Even with the reduction in crop and pasture land, livestock output is higher at the global level for the price sensitive scenario compared to the baseline (Figure 6). While most regions had a decline in deforestation under the price sensitive scenario, four regions had an increase, which includes BRAZIL, C_C_Amer, MEAS_NAfr, and S_S_AFR. The regions having the most reduction in deforestation are CHIHKG, INDIA, Mal_Indo, R_SE_Asia, and Rest of South Asia (R_S_Asia). Most of these regions are also the regions with the largest decrease in the cropland area (Table 4).

Table 5 compares total emissions from the baseline simulation to the emissions of the price sensitive scenario. At the global level, the total emissions with the reduced SUBPAR are about 17.5 billion tons of $\mathrm{CO}_{2}$ e, approximately 2.3 billion tons less (about 11\% less) than the baseline simulation. The $11 \%$ drop in emissions is mainly

\footnotetext{
${ }^{4}$ Figure 6 shows the percentage point difference in global livestock output growth for price sensitive scenario compared to the baseline scenario. This figure is not directly comparable to Figure 3, which shows percentage change in global livestock output for the baseline scenario.
} 


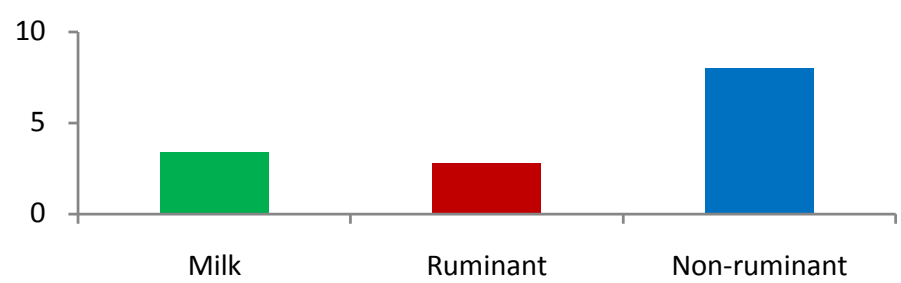

Figure 6. Percentage point difference in the global livestock output growth with the reduced SUBPAR compared to the baseline simulation.

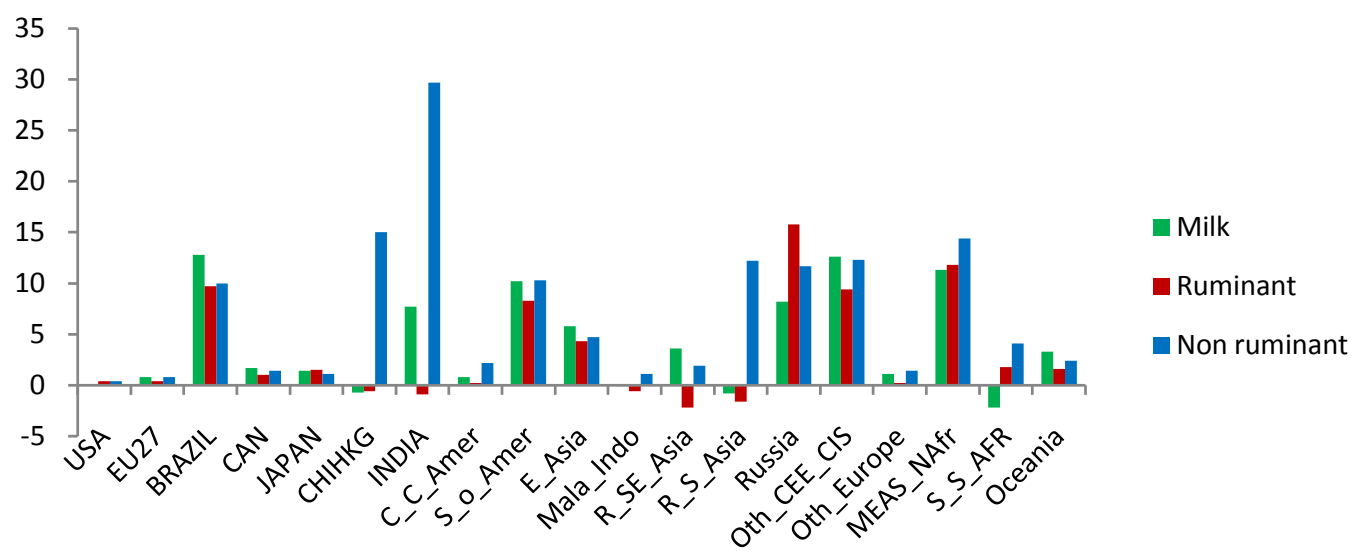

Figure 7. Percentage point difference in the regional livestock output growth with the reduced SUBPAR compared to the baseline simulation.

Table 4. Impact of higher substitution in livestock consumption on land use chage (in hectare).

\begin{tabular}{|c|c|c|c|c|c|c|c|c|c|}
\hline \multirow[t]{2}{*}{ GTAP-BIO regions } & \multicolumn{3}{|c|}{$\begin{array}{l}\text { Land use change due to change } \\
\text { in the demand for livestock output } \\
\text { obtained from in the } \\
\text { baseline scenarios (A) }\end{array}$} & \multicolumn{3}{|c|}{$\begin{array}{l}\text { Land use change due to change in the } \\
\text { demand for livestock output obtained } \\
\text { from the reduced SUBPAR } \\
\text { parameters scenarios (B) }\end{array}$} & \multicolumn{3}{|c|}{$\begin{array}{l}\text { Difference in land use change due to } \\
\text { reduced SUBPAR } \\
(\mathrm{C}=\mathrm{B}-\mathrm{A})\end{array}$} \\
\hline & Forest & Cropland & Pasture & Forest & Cropland & Pasture & Forest & Cropland & Pasture \\
\hline USA & $(280,016)$ & $(26,032)$ & 305,936 & $(256,992)$ & $(48,096)$ & 305,104 & 23,024 & $(22,064)$ & $(832)$ \\
\hline EU27 & $(121,680)$ & (7488) & 129,212 & $(114,896)$ & $(20,176)$ & 135,004 & 6784 & $(12,688)$ & 5792 \\
\hline BRAZIL & $(4,204,000)$ & $(430,460)$ & $4,634,288$ & $(4,568,416)$ & $(527,912)$ & $5,096,464$ & $(364,416)$ & $(97,452)$ & 462,176 \\
\hline CAN & $(113,376)$ & 41,208 & 72,114 & $(107,440)$ & 32,292 & 75,206 & 5936 & (8916) & 3092 \\
\hline JAPAN & $(7640)$ & $(1861)$ & 9503 & (7618) & $(2860)$ & 10,475 & 22 & (999) & 973 \\
\hline CHIHKG & $(18,803,440)$ & $2,440,520$ & $16,363,040$ & $(15,675,056)$ & 674,496 & $15,000,576$ & $3,128,384$ & $(1,766,024)$ & $(1,362,464)$ \\
\hline INDIA & $(678,732)$ & $(75,184)$ & 753,938 & $(481,876)$ & $(271,136)$ & 753,042 & 196,856 & $(195,952)$ & (896) \\
\hline C_C_Amer & $(166,356)$ & $(22,488)$ & 188,832 & $(172,464)$ & $(21,672)$ & 194,184 & (6108) & 816 & 5352 \\
\hline S_o_Amer & $(3,472,112)$ & $(272,012)$ & $3,744,208$ & $(3,421,528)$ & $(325,448)$ & $3,746,944$ & 50,584 & $(53,436)$ & 2736 \\
\hline E_Asia & $(136,132)$ & (7582) & 143,720 & $(126,620)$ & $(14,378)$ & 140,992 & 9512 & (6796) & (2728) \\
\hline Mala_Indo & $(429,544)$ & 95,640 & 333,937 & $(102,092)$ & $(196,864)$ & 298,957 & 327,452 & $(292,504)$ & $(34,980)$ \\
\hline R_SE_Asia & $(687,912)$ & $(31,856)$ & 719,812 & $(489,032)$ & $(184,228)$ & 673,275 & 198,880 & $(152,372)$ & $(46,537)$ \\
\hline R_S_Asia & $(423,938)$ & $(1,582,812)$ & $2,006,784$ & $(98,976)$ & $(1,295,420)$ & $1,394,360$ & 324,962 & 287,392 & $(612,424)$ \\
\hline Russia & $(466,064)$ & $(21,344)$ & 487,464 & $(389,280)$ & $(82,136)$ & 471,360 & 76,784 & $(60,792)$ & $(16,104)$ \\
\hline Oth_CEE_CIS & $(243,572)$ & $(148,840)$ & 392,352 & $(205,360)$ & $(197,128)$ & 402,688 & 38,212 & $(48,288)$ & 10,336 \\
\hline Oth_Europe & (3368) & (1289) & 4659 & (3316) & (1515) & 4840 & 52 & (226) & 181 \\
\hline MEAS_NAfr & $(13,054)$ & $(80,708)$ & 93,744 & $(13,435)$ & $(100,072)$ & 113,520 & (381) & $(19,364)$ & 19,776 \\
\hline S_S_AFR & $(13,071,280)$ & $(907,216)$ & $13,978,688$ & $(13,245,584)$ & $(1,524,080)$ & $14,769,792$ & $(174,304)$ & $(616,864)$ & 791,104 \\
\hline Oceania & $(38,498)$ & $(60,884)$ & 99,456 & $(34,076)$ & $(73,100)$ & 107,136 & 4422 & $(12,216)$ & 7680 \\
\hline World & $(43,360,713)$ & $(1,100,688)$ & $44,461,687$ & $(39,514,057)$ & $(4,179,433)$ & $43,693,919$ & $3,846,657$ & $(3,078,745)$ & $(767,767)$ \\
\hline
\end{tabular}


Table 5. Impact on induced emissions (in 1000 tons $\mathrm{CO}_{2}$ eq.) with the reduced SUBPAR.

\begin{tabular}{|c|c|c|c|c|c|c|c|c|}
\hline \multirow{2}{*}{ GTAP-BIO regions } & \multicolumn{5}{|c|}{ Land conversion sequences } & \multirow{2}{*}{$\begin{array}{l}\text { Emissions with } \\
\text { the new SUBPAR } \\
\text { (D) }\end{array}$} & \multirow{2}{*}{$\begin{array}{l}\text { Emissions in the } \\
\text { baseline } \\
\text { simulations (E) }\end{array}$} & \multirow{2}{*}{$\begin{array}{l}\text { Difference in } \\
\text { emissions } \\
\text { (D-E) }\end{array}$} \\
\hline & F-to-C & C-to-F & C-to-P & C-to-CP & F-to-P & & & \\
\hline USA & 14,074 & 0 & -4322 & $-74,787$ & 59,772 & -5263 & 12,239 & $-17,502$ \\
\hline EU27 & 88 & 0 & -2813 & 0 & 23,886 & 21,161 & 24,431 & -3270 \\
\hline BRAZIL & 0 & 0 & $-95,183$ & $-187,099$ & $3,158,970$ & 2,876,688 & 2,666,693 & 209,995 \\
\hline CAN & 17,645 & 0 & -324 & 0 & 19,757 & 37,079 & 40,064 & -2986 \\
\hline JAPAN & 345 & 0 & -879 & 0 & 1528 & 994 & 1272 & -278 \\
\hline CHIHKG & 768,930 & 0 & $-38,790$ & 0 & $4,494,995$ & $5,225,136$ & $6,648,973$ & $-1,423,837$ \\
\hline INDIA & 26,252 & 0 & $-28,145$ & 0 & 226,234 & 224,342 & 359,791 & $-135,449$ \\
\hline C_C_Amer & 0 & 0 & -5179 & 0 & 95,967 & 90,789 & 87,112 & 3677 \\
\hline S_o_Amer & 3 & 0 & $-75,799$ & 0 & $1,789,402$ & $1,713,605$ & $1,752,116$ & $-38,510$ \\
\hline E_Asia & 114 & 0 & -1191 & 0 & 13,351 & 12,273 & 14,414 & -2141 \\
\hline Mala_Indo & 0 & 0 & $-47,713$ & 0 & 86,104 & 38,390 & 496,087 & $-457,697$ \\
\hline R_SE_Asia & 484 & 0 & $-37,947$ & 0 & 298,009 & 260,546 & 413,346 & $-152,800$ \\
\hline R_S_Asia & 9134 & 0 & $-67,321$ & 0 & 46,576 & $-11,611$ & 199,788 & $-211,400$ \\
\hline Russia & 8194 & 0 & -9383 & 0 & 39,032 & 37,844 & 56,114 & $-18,270$ \\
\hline Oth_CEE_CIS & 0 & 0 & $-17,162$ & 0 & 40,151 & 22,989 & 35,653 & $-12,664$ \\
\hline Oth_Europe & 0 & -12 & -303 & 0 & 434 & 119 & 177 & -59 \\
\hline MEAS_Nafr & 0 & 0 & -7369 & 0 & 5125 & -2244 & -1092 & -1153 \\
\hline S_S_Afr & 122,084 & 0 & $-137,012$ & 0 & $6,958,418$ & $6,943,490$ & $6,947,606$ & -4115 \\
\hline Oceania & 32 & 0 & -3690 & 0 & 14,887 & 11,230 & 14,193 & -2963 \\
\hline World & 967,380 & -12 & $-580,524$ & $-261,885$ & $17,372,597$ & $17,497,556$ & $19,768,978$ & $-2,271,422$ \\
\hline
\end{tabular}

due to the decrease in deforestation and the increased conversion of crop land for pasture (Table 3 and Table 5). The regions with the substantial reduction in emissions are CHIHKG, Mala_Indo, R_SE_Asia, R_S_Asia, and INDIA (Table 5). The results indicate that increased price sensitivity in consumption of livestock products can lead to a substantial reduction in the GHG emissions from the sector.

\section{Conclusions}

Based on regional projections of GDP, population, capital, and skilled and unskilled labor, demand for livestock outputs are forecasted for the period between the years 2004 to 2022. Globally, the demand for non-ruminant output increases the most. Regionally, this expansion is the most evident in fast-growing economies such as CHIHKG and INDIA.

Changes in land use as a result of the growth in livestock output are estimated to be large with a loss of forest amounting to over 43.3 million hectares, a reduction in crop land of about 1 million hectares, and an increase in pasture of over 44 million hectares. Given that the forests sequester more carbon than other land uses, clearing them results in significant GHG emissions. The change in land use due to increased livestock production increases emissions by about 20 billion tons of $\mathrm{CO}_{2}$ e between 2004 and 2022 or about an average of 1.1 billion tons annually, which is about $15.5 \%$ of the total emissions (7.1 billion tons of $\mathrm{CO}_{2}$ e) from livestock sector as estimated by [2] and about $2.2 \%$ of the total human-induced GHG emissions (49 billion tons of $\mathrm{CO}_{2}$ e) as estimated by the Intergovernmental Panel on Climate Change for the year 2004 [15]. When consumer's responses to price changes are made more elastic i.e. more sensitive to price changes and willing to substitute more readily among livestock products, there is more increase in demand for livestock output especially the non-ruminant products with significant reduction in deforestation and GHG emissions. 
The results from this study indicate that there is a potential for significant reduction in GHG emissions from livestock sector through policy interventions that target the consumption pattern of the private households. For this purpose, the intervention should encourage increased substitution among livestock products. In particular, the policies should encourage consumers to substitute non-ruminant for ruminant meat products.

\section{Acknowledgements}

The authors are grateful for the financial support from the University of Nebraska-Lincoln and Fort Hays State University.

\section{References}

[1] Caro, D., Davis, S. and Bastianoni, S. (2014) Global and Regional Trends in Greenhouse Gas Emissions from Livestock. Climatic Change, 126, 203-216. http://dx.doi.org/10.1007/s10584-014-1197-x

[2] Gerber, P., Steinfeld, H., Henderson, B., Mottet, A., Opio, C., Dijkman, J., Falcucci, A. and Tempio, G. (2013) Tackling Climate Change through Livestock-A Global Assessment of Emissions and Mitigation Opportunities. Food and Agriculture Organization of the United Nations (FAO), Rome.

[3] Steinfeld, H., Gerber, P., Wassenaar, T., Castel, V., Rosales, M. and de Haan, C. (2006) Livestock’s Long Shadow: Environmental Issues and Options. Food and Agriculture Organization of the United Nations (FAO), Rome.

[4] FAO (2011) World Livestock 2011—Livestock in Food security. Food and Agriculture Organization of the United Nations (FAO), Rome.

[5] Herrero, M., Gerber, P., Vellinga, T., Garnett, T., Leip, A., Opio, D., Westhoek, H., Thornton, P., Olsen, J., Hutchings, N., Montgomery, H., Soussana, J., Steinfeld, H. and McAllister, T. (2011) Livestock and Greenhouse Gas Emissions: The Importance of Getting the Numbers Right. Animal Feed Science and Technology, 166-167, 779-782. http://dx.doi.org/10.1016/j.anifeedsci.2011.04.083

[6] Goodland, R. and Anhang, J. (2009) Livestock and Climate Change: What If the Key Actors in Climate Change Are Cows, Pigs, and Chicken? World Watch, November/December.

[7] Hertel, T. (1997) Global Trade Analysis Project: Modeling and Applications. Cambridge University Press, Cambridge.

[8] Hertel, T., Golub, A., Jones, J., O’Hare, M., Plevin, R. and Kammen, D. (2010) Effects of U.S. Maize Ethanol on Global Land Use and Greenhouse Gas Emissions: Estimating Market Mediated Responses. Bioscience, 60, 223-231. http://dx.doi.org/10.1525/bio.2010.60.3.8

[9] Tyner, W., Taheripour, F., Zhuang, Q. and Baldos, U. (2010) Land Use Changes and Consequent $\mathrm{CO}_{2}$ Emissions Due to U.S. Corn Ethanol Production: A Comprehensive Analysis. Department of Agricultural Economics, Purdue University, Indiana.

[10] Taheripour, F., Hertel, T. and Tyner, W. (2011) Implications of Biofuels Mandate for the Global Livestock Industry: A Computable General Equilibrium Analysis. Agricultural Economics, 42, 325-342. http://dx.doi.org/10.1111/j.1574-0862.2010.00517.x

[11] Taheripour, F. and Tyner, W. (2013) Biofuels and Land Use Change: Applying Recent Evidence to Model Estimates. Applied Sciences, 3, 14-38. http://dx.doi.org/10.3390/app3010014

[12] Plevin, R., Gibbs, H., Duffy, J., Yui, S. and Yeh, S. (2014) Agro-Ecological Zone Emission Factor (AEZ-EF) Model (v47): A Model of Greenhouse Gas Emissions from Land-Use Change for Use with AEZ-Base Economic Models. GTAP Technical Paper No. 34. Global Trade Analysis Center, Purdue University, Indiana.

[13] Foure', J., Benassy-Que'ere’, A. and Fontangne’, L. (2012) The Great Shift: Macroeconomic Projections for the World Economy at the 2050 Horizon. Centre d'Études Prospectives et d’Informations Internationales (CEPII), France. http://www.cepii.fr/francgraph/doctravail/resumes/wp resume.asp?annee=2012\&ref=3\&NoDoc $=4179$

[14] Chappuis, T. and Walmsley, T. (2011) Projections for World CGE Model Baselines. GTAP Research Memorandum No. 22. Center for Global Trade Analysis, Purdue University, Indiana.

[15] IPCC (2007) Climate Change 2007: Synthesis Report. Contribution of Working Groups I, II and III to the Fourth Assessment Report of the Intergovernmental Panel on Climate Change, Intergovernmental Panel on Climate Change, Geneva. 